\title{
Prevalence and Perception of Pharmacists on Dispensing Prescription Only Medication without Prescription in Makurdi, Benue State, Nigeria
}

\author{
A. Tor-Anyiin, A. E. Gwa, R. Okonkwo, I. Tor-Anyiin, and A. Abuh
}

\begin{abstract}
Background: Currently in Nigeria, prescription only medicines are supposed to be dispensed only with a prescription. The study aimed to reveal the prevalence of prescription only medicine without a prescription and the perception of community pharmacist in Makurdi, Benue State Nigeria towards the phenomenon.

Method: The study was carried out between February-April 2019 using simulated patient approach and administration of questionnaire on the pharmacists.

Result: Forty pharmacies were surveyed and $100 \%$ (29) of the respondents were willing to dispense prescription only medicines without a prescription. Among the respondents, 93\% (27) said they do see up to an estimated $30 \%$ of POMs without a prescription daily. While $19.2 \%$ (5) of the pharmacists do dispense POM without a prescription, $42.3 \%$ (11) said they do so depend on the level of education or prior exposure of the client to the medication. Only $38.5 \%$ (10) said they will not dispense a POM without a prescription. Most of the pharmacists, 93\% (27) agreed that dispensing POM without with a prescription holds potentials for drug abuse, drug misuse, drug dependence with attendant economic consequences.

Conclusion: A vast majority of practicing community pharmacists in Nigeria are willing and do dispense prescription-only medications without a valid prescription; for a variety of reasons. This is against existing Nigerian pharmacy laws and the national drug policy.
\end{abstract}

Index Terms - dispensing; perception; prescription; prevalence.

\section{INTRODUCTION}

Drug misuse and abuse play a significant impact on human lives and human productivity. According to the United Nations Office on Drugs and Crime (UNODC), drug-related mortality in 2012 for population aged 15-64 alone was estimated to be 40 deaths in a million (UNODC, 2014). Some of these drug-related deaths could be traced to misuse of medicines which are purchased without a valid prescription. The negative toll of drug misuse and abuse on the society is enormous as it affects all aspect of the society ranging from physical injuries at work, loss of job, road traffic accidents to broken romantic relationships, broken family and personal relationships, and mental illness [2]-[4].

Published on June 17, 2020

A. Tor-Anyiin, Medecins sans Frontieres, Canada.

(corresponding e-mail: toranyiin ${ }^{\circledR}$ gmail.com).

A. E. Gwa, Pharmacists Council of Nigeria, Nigeria.

R. Okonkwo, Principal Health Consulting Limited, Nigeria.

I. Tor-Anyiin, ,Federal Medical Center Makurdi, Nigeria.

A. Abuh, Nuffield Health Guildford Hospital, UK.
In an ideal setting, prescription - only medicines (POM) are to be dispensed only by pharmacists or people who are trained and certified to dispense such prescribed drugs in contrast to over the counter (OTC) drugs which could be obtained without prescription. The reality, however, is quite different as prescription only medicines are dispensed without prescriptions as required by the regulatory agencies and this practice is not unique to Nigeria [5]. There is a plethora of drug-regulating agencies in Nigeria which include National Agency for Food and Drug Administration and Control (NAFDAC), National Drug Law Enforcement Agency (NDLEA), and the Pharmacists Council of Nigeria (PCN). These agencies work synergistically to ensure that best practices are observed in the handling of drugs in Nigeria and, ensure or enforce rational drug prescription and dispensing. According to the Conference of Experts on the Rational use of Drugs that met in Nairobi in 1985, "Rational use of drugs requires that patients receive medications appropriate to their clinical needs, in doses that meet their own individual requirements for an adequate period of time, and the lowest cost to them and their community". Going by this, only the right drug, in right dosage form in the right dose is supposed to be prescribed and dispensed to the right patient for the right duration [6], [7].

Published research indicates that prescription-only drugs are available without a prescription to varying degrees in different parts of the world - both in the developed and developing world. In Saudi Arabia, there are documented reports of more than 35\% POM been dispensed over the counter and this has attendant implications [8]. In the USA, an online study of 138 unique vendors revealed that $36.2 \%$ sold antibiotics without prescription from internet pharmacies; availability of penicillin and macrolide without prescription on $94.2 \%$ and $96.4 \%$ of the sites respectively; while for cephalosporin and fluoroquinolones it was $61.6 \%$ and 56.5\% respectively [9]. In Spain, the prevalence of dispensing POMs without a prescription was found to be 79.7\% [55] for antibiotics meant for urinary tract infections while $34.8 \%$ [24] was observed for sore throat infection in the study [10]. A global systematic review of studies on use of antibiotics without prescription showed a pooled proportion of antibiotics for non-prescriptions to be $62 \%$ [11]. Some of the POMs are purchased from pharmacy for self-medication purposes without a prescription and the attendant consequences are enormous. For example, pharmacies that dispense without a prescription have been shown to supply more than a single course of antibiotics compared with those that require an interview [9]; raising the spectre of antibiotic resistance. Antibiotics are POMs in 
Nigeria but a study in the Middle-Belt region of the country showed that $60.9 \%$ (262) would simply walk into a pharmacy and buy an antibiotics for common cold while in the same study, $52.6 \%$ (226) said they will be no need to see a doctor for a prescription if they know the indication of an antibiotic [12], [13].

Consequences of drug misuse which is the use of a drug for reasons not consistent with its indication medically or legally [14] could range from psychological, adverse events, social, addiction, physical, and legal problems due to intoxication to dependence (National Collaborating Centre for Mental Health, 2008). The implication of nonprescription supply by pharmacies could lead to death as well. In 2012, a young postgraduate female student in Nigeria was drugged with Flunitrazepam, raped and killed [15]. The killers were apprehended which led to the arrest of the pharmacists that dispensed the intermediate-acting benzodiazepine without a prescription whereas the drug is strictly a POM in Nigeria [6]. Similar incidents also exist though many are not documented. The economic implication of dispensing POMs without a prescription are also many. For example, a self-medicated POM could lead to further complication of a medical condition that would lead to additional cost for further treatment in a hospital. A portion of the Pharmacist Oath (taken by every graduating pharmacy student in Nigeria) reads. "I shall apply the full measure of my knowledge, skills and abilities to improving the health and wellbeing of all those I serve and place their needs above my personal interest and considerations" (PCN New Pharmacists' Oath, 2015). This means pharmacists and pharmacy have a role to play to minimize prevalence of dispensing POMs without prescriptions in Nigeria. Our research, therefore, aims to assess prevalence of the practice of dispensing POMs without prescription in licensed pharmacies and to explore the perception of pharmacists on dispensing POMs without prescription in Makurdi, Benue State, Nigeria.

\section{MethodOLOGY}

\section{A. Population and study area}

The study area for the survey was Makurdi metropolis. Makurdi, the capital city of Benue State is located along the Benue River in the Middle-Belt region of Nigeria and the city has an estimated population of 300,330 (2006 National Population Census, most recent census). This was a mixed study with a cross-sectional design for data collection [16], [17]. Sample size was determined using the Leslie and Kish formula [18]

$$
n=\frac{Z^{2} p q}{\delta^{2}} N,(1)
$$

where,

$N$ - the sample size required;

$Z$ - the critical value that corresponds to the selected significance criteria (significance level or level of alpha) and confidence interval of $95 \%=1.96$;

$p$ - the proportions of the attribute in the population under investigation. We use the prevalence for dispensing of Sildenafil citrate (Viagra), a POM without prescription from a study in Addis Ababa in Ethiopia which was 96.55\% [19]. $\delta$ (Delta) - equals the total width of the expected CI (marginal error), and we assumed 6\%;

$\mathrm{q}=1-\mathrm{p}$.

From the given parameters, $n=36$. Additional $10 \%$ in case a pharmacy was closed during a visit makes it 40 . Therefore, a total of 40 pharmacies were surveyed in Makurdi.

\section{B. Ethical permission}

Ethical approval for the study was obtained from the office of the Honorable Commissioner of Health, at the Benue State Ministry of Health. Anyone who willingly accepted to respond to the questionnaire was assumed to have consented to participation and the research was restricted to only registered pharmacies in Makurdi.

\section{Sampling technique}

After the list of all registered pharmacies was obtained from the office of the Directorate for Pharmaceutical Services, Benue State, we used a simple random sampling technique [20]. All the pharmacies were assigned serial numbers and an online random integer generator used to generate random numbers (www.random.org). We started from the first pharmacy premise generated and followed the sequence of generated numbers to the required sample size of 50 .

\section{Method of data collection}

First, five randomly selected physicians based in Makurdi with at least ten years of practice experience were contacted to list ten common POMs they know their patients use without prescription based on their experience from interaction with patients. The lists were pooled and six POMs with the highest frequencies were identified for the study. These were Amlodipine, Amoxicillin, Ciprofloxacin, Metformin, Metronidazole, and Amiloride/ Hydrochlorothiazide. A simulated - patient approach was used where research assistants disguised as clients to buy prescription only medicines without a prescription [21]. These drugs were simply written on a plain sheet of paper without any prescriber's name or signature and neither date nor name of the client. Then two Research Assistants were trained on how to act as a patient and sent to these pharmacies with the drug list and attempt to purchase the medicines. In the second part of the research, a one-page questionnaire with two sections was piloted on five pharmacists who were later exempted from the main study. The first section had three questions to estimate the prevalence of clients who come to the pharmacy for a POM without a prescription in a day. The questions included whether among clients who come to buy POM daily they were those with POM without prescription. What was the estimated prevalence of request for POMs without a prescription among POM requests on a daily basis and if the pharmacist would dispense a POM without a prescription. The second section sought to know the perception of Pharmacists on clients who seek to buy POM without prescription. Some of the items included 'Dispensing POM without prescription should be discouraged', 'If I do not dispense, patent medicine vendors would'; 'Dispensing POM without prescription is against the law'; 'Dispensing POM without a prescription has a potential for drug abuse, misuse, drug dependence and drug addiction'. The 
questionnaire was found to be easy to self-administer within five minutes. The Research Assistants went to the same pharmacies in the first study with the one-page questionnaire attached to an introduction letter (an overview of the research) and administered the questionnaire (appendix 1). The data collection lasted from 1st February 30th April 2019. Throughout the data collection, only the code numbers were used in order to mask the identities of the pharmacy premises.

\section{E. Instrument}

A 5-point Likert scale (1=Strongly disagreed, 2=Disagreed, 3=Undecided, 4=Agreed and 5=Strongly agreed) was used to rate the perception of pharmacists in dispensing POM without prescription (Bishop \& Herron, 2015.). The Cronbach alpha coefficient for the instrument was 0.963 .

\section{F. Data analysis}

Part of the data obtained was imported into SPSS v 25.0 and descriptive statistics generated for analysis.

\section{RESULTS}

In the first part of the study, $100 \%(n=40)$ of the surveyed pharmacies were willing to dispense all the six POMs in the generated drug list without a prescription. See Table I. One of the pharmacies had no Ciprofloxacin, another did not have Metformin and a third had no Amiloride/Hydrochlorothiazide. In each of the scenarios, the salesperson was willing to dispense the medicines if available. In all the surveyed pharmacies it was only in $16 \%$ [8] that a pharmacist was the first point of contact with the simulated patients and all of them were willing to dispense any of the POMs without prescription just as the pharmacy assistants. Some of the indices for knowing if the drug was going to be dispensed was if the pharmacist/pharmacy assistant took the piece of paper from the simulated patient, read it, estimated the cost and requested the client to pay. Or, if the pharmacy assistant collected the prescription, estimated the cost or consulted the pharmacist and returned to the simulated patient asking for payment. Two pharmacists in two different pharmacies inquired to know if the drugs were prescribed by a physician and even when the simulated patient responded in the negative, there was still willingness to dispense. No question was asked if the client had any knowledge of the indications of the drugs.

TABLE I: LIST OF DRUgS Whose AVAILABILITY Without PRESCRIPTION WAS SURVEYED

\begin{tabular}{lcl}
\hline \multicolumn{1}{c}{ Drug } & $\begin{array}{c}\text { Available } \\
\text { without } \\
\text { prescription }\end{array}$ & \multicolumn{1}{c}{$\begin{array}{c}\text { Therapeutic } \\
\text { class }\end{array}$} \\
\hline Amlodipine & $100 \%$ & Antihypertensive \\
Amoxicillin & $100 \%$ & Antibiotic \\
Ciprofloxacin & $98 \% *$ & Antibiotic \\
Metformin & $98 \% *$ & Antidiabetic \\
Metronidazole & $100 \%$ & Antibiotic \\
Amiloride/Hydrochlorothiazide & $98 \% *$ & Antihypertensive \\
\hline
\end{tabular}

* Drug was out of stock in one of the pharmacies.

In the first section of the second part of the study, response rate was $72.5 \%$ (29). Among the responses, $93.1 \%$
(27) answered in affirmative to the first question of whether clients do come to buy POM without a valid prescription daily while $6.9 \%$ (2) said no. On the second question about the estimated daily prevalence of request for POM without a prescription, response rate was $65 \%$ (26). Among the respondents, $34.6 \%$ (9) said up to $30 \%$ of daily request for POM was without a prescription while $23.1 \%$ (6) said it was less than $10 \%$. While $7.7 \%$ (2) said daily request for POM without prescription was more than $70 \%$ of POM requests. On the willingness to dispense POM without a prescription, response rate was $65 \%$ with $19.2 \%$ (5) willing to dispense. For $42.3 \%$ (11) of the respondents, whether they will dispense was dependent on other factors such as knowledge of the client on the drug, level of education of the client, if the client sounds convincing that the drug was meant for a relative who was already on the drug among others. For $38.5 \%$ (10), they will not dispense a POM without a valid prescription while $19.2 \%$ (5) said they will dispense a POM without prescription (Table II).

TABLE II: DISPENSING POM WITHOUT PRESCRIPTION

\begin{tabular}{lc}
\hline \multicolumn{1}{c}{ Question } & Frequency $(\%)$ \\
\hline 1. Do clients come to buy POM without & \\
prescription in your business premise & $2(6.9)$ \\
No & $27(93.1)$ \\
Yes & $29(100)$ \\
Total & \\
\hline 2. By your estimate, among POM & \\
request, what would be the daily & \\
prevalence of POM request without & \\
prescription? & $6(23.1)$ \\
Less than 10\% & $9(34.6)$ \\
Between 11\%-30\% & $5(19.2)$ \\
Between 31-50\% & $4(15.4)$ \\
Between 51\% - 70\% & $2(7.7)$ \\
Greater than 70\% & $2(100.0)$ \\
Total & \\
\hline 3. Do you dispense POM to clients who & \\
do not have the required prescription? & $10(38.5)$ \\
No & $5(19.2)$ \\
Yes & $11(42.3)$ \\
Depends & $26(100.0)$ \\
Total &
\end{tabular}

In the second section of part 2 of the study, a Likert scale was used to obtain data on perception of pharmacists on dispensing of POM without prescription. The median response for the first question on whether dispensing of POM without a prescription helps clients who cannot afford to a see a doctor was 3.0. Those who believed that dispensing a POM without a prescription helps to reduce treatment cost had a median of 3.5. Among the respondents, those who thought dispensing POM without a prescription shortens the process to get medical services had a median of 3.0. Among the respondents, those who perceived that dispensing POM without prescription holds potentials for drug abuse, drug misuse, drug dependence with attendant economic consequence, the median was 4.0. The median for those who think dispensing POM without a prescription should be encouraged was 1.0 while for those who thought doing so was against the law of medical practice the median was 4.0. The median for those who think the practice should be discouraged was 4.0 while those who thought that even if they do not dispense a POM without a prescription, their colleagues would do so was 4.0. Majority of the pharmacists indicated that if they do not dispense a POM without a 
prescription, patent and proprietary medicine vendors (PPMV) would do so. The median for this category was 5.0. Lastly, the median for those who supported the view that if the client knew the drug indication, dispensing the POM without a prescription was in order was 2.0 (Table III).

TABLE III. PHARMACISTS PERCEPTION OF DISPENSING POM WITHOUT PRESCRIPTION

\begin{tabular}{|c|c|c|c|c|c|c|}
\hline \multirow[b]{2}{*}{ Variable } & \multicolumn{5}{|c|}{ Frequency (\%) } & \multirow[b]{2}{*}{ Median } \\
\hline & $\begin{array}{l}\text { Strongly } \\
\text { disagreed }\end{array}$ & Disagreed & Undecided & Agreed & $\begin{array}{l}\text { Strongly } \\
\text { agreed }\end{array}$ & \\
\hline $\begin{array}{l}\text { Helps clients who cannot afford } \\
\text { to see a doctor }\end{array}$ & $2(10.5)$ & $5(26.3)$ & $5(26.3)$ & $4(21.1)$ & $3(15.8)$ & 3.0 \\
\hline Helps reduce treatment costs & $5(16.7)$ & $8(26.7)$ & $2(6.7)$ & $10(33.3)$ & $5(16.7)$ & 3.5 \\
\hline $\begin{array}{l}\text { Helps shortens the process of } \\
\text { accessing drugs for clients }\end{array}$ & $6(20.7)$ & $8(27.6)$ & $3(10.3)$ & $11(37.9)$ & $1(3.4)$ & 3.0 \\
\hline $\begin{array}{l}\text { Potential for: abuse, misuse, } \\
\text { dependence, addiction, } \\
\text { resistance, and adverse economic } \\
\text { implications }\end{array}$ & $2(6.9)$ & $0(0.0)$ & $0(0.0)$ & $14(44.8)$ & $13(44.8)$ & 4 \\
\hline Should be encouraged & $16(55.2)$ & $6(20.7)$ & $4(13.8)$ & $1(3.4)$ & $2(6.9)$ & 1.0 \\
\hline It is against the law & $6(20.0)$ & $1(3.3)$ & $4(13.3)$ & $7(23.3)$ & $12(40.0)$ & 4.0 \\
\hline Should be discouraged & $2(6.9)$ & $2(6.9)$ & $5(17.2)$ & $11(37.9)$ & $9(31.0)$ & 4.0 \\
\hline $\begin{array}{l}\text { Even if I (pharmacist) do not } \\
\text { dispense, other retail/ community } \\
\text { pharmacies will dispense }\end{array}$ & $0(0.0)$ & $4(13.8)$ & $5(17.2)$ & $7(24.1)$ & $13(44.8)$ & 4.0 \\
\hline $\begin{array}{l}\text { Even if I (pharmacist) do not } \\
\text { dispense, patent medicine store } \\
\text { owners will dispense }\end{array}$ & $0(0.0)$ & $3(10.3)$ & $3(10.3)$ & $6(20.7)$ & $17(58.6)$ & 5.0 \\
\hline $\begin{array}{l}\text { I think if the client knows what } \\
\text { the } \operatorname{drug}(\mathrm{s}) \text { is/are meant for there } \\
\text { will be no problem }\end{array}$ & $10(34.5)$ & $12(41.4)$ & $3(10.3)$ & $2(6.9)$ & $2(6.9)$ & 2.0 \\
\hline
\end{tabular}

\section{DISCUSSION}

Dispensing POMs without a prescription enhances selfmedication as people can get medicines of choice easily. Although self-medication has some benefits, it also has several and well-known risks and consequences; especially non-responsible self-medication [23]. In Nigeria, there is low health literacy level as such the understanding of most people on healthcare information in order to make informed health decision cannot be guaranteed [24]. By the tenet of pharmacy practice regulation in Nigeria, the practice of pharmacists dispensing POMs without prescription is frowned upon. Drug abuse, drug misuse and drug resistance are facilitated when POMs are dispensed without prescription as those who desire could easily access such medicines. In a world-wide survey of antibiotic resistance by the World Health Organization, 57\% of the surveyed medical practitioners felt there is nothing they can do to stop antibiotic resistance [25]. This cannot be far from the truth if the causes of drug resistance are known, it becomes easier to at least minimize it. Studies in northern parts of Nigeria shows that $90 \%$ of both community pharmacists and patent medicine vendors understand that dispensing antibiotics (POMs) without prescription contributes to antibiotic resistance [26], [27]. Among the respondents, 93.1\% admitted they do see requests for POMs without prescription on daily basis. This underscores the endemicity of the practice of dispensing POMs without prescription as clients would only keep coming for POM without prescription if their request is always serviced.

The main and common source of medicine for many Nigerians remains the PPMVs that are in every nook and cranny of the country especially in rural settlements. In a systematic review of studies on PPMV practice in Nigeria, $20 \%$ of them did not have more than the basic primary school education [28]. In order to achieve universal health services in the country, these PPMVs are very essential in the provision of basic health services [29]. However, it is a known fact that these PPMVs relative to community pharmacists have very low level of health knowledge and most PPMVs are also known to operate illegally. Lagos state is estimated to have over 27,000 PPMVs and only $6 \%$ have "practicing" license with only $38 \%$ having registration with the regulatory agency, the Pharmacist Council of Nigeria [28]. The illicit practice of these PPMVs in terms of provision of health services, including the stocking of drugs well outside their legally permitted list; especially POMs, is also well documented [30]. It is, therefore, not surprising that almost $80 \%$ (Agreed/strongly agreed) of respondents in this study (Pharmacists) think if they do not dispense POMs without prescription, clients will have such requests filled by PPMVs. However, this is not a justifiable reason. By the tenets of the pharmacy training, they are expected to know the health implication of dispensing POMs without a valid prescription. Among the respondents, $68.9 \%$ (Agreed/Strongly agreed) also think if they do not dispense POM without prescription, their fellow pharmacist colleagues would dispense. This perception is worrisome and only underscores the enormity of work that needs to be done in the regulation of pharmacy practice in Nigeria. It also completely negates the portion of their Oath that demands of them not to consider pecuniary interest over the health and safety of their clients (PCN Oath for Pharmacists, 2015). No health professional is expected to engage in illicit health practice simply because someone along the line will surely do same. The Pharmacists Council of Nigeria that 
regulates both PPMVs and pharmacy practice in the country need to investigate this practice to stem it.

More than a third (38\%) of the pharmacists indicated that they will not dispense POM without a prescription. This was in direct contrast with what our simulated patients experienced as there was no single pharmacy that refused to honour the request to buy the listed six POMs even when there was no prescription. Could it be that the pharmacists (presumably supervising pharmacy assistants/salespersons) are not aware that POMs are been sold without prescription in their pharmacy? Could it be concealment of fact or a case of saying one thing and practicing the direct opposite? Community pharmacists have the responsibility of ensuring optimal use of medicines and patient safety and as such are expected to ensure all practices by the associate staff are in line with the best practices of the profession. Among the respondents, $19.2 \%$ said they do dispense POM without prescription. This is a high number and it shows there are some malpractices in the noble profession as it is obtainable in many other medical professions [31]. There is need for a public awareness by the regulatory agency so that pharmacists in community practice would ensure there is no POM dispensed without prescription.

Among the respondent's pharmacists, almost half (42\%) said they would dispense a POM without a prescription depending on some conditions. The conditions listed include knowledge of the client on the drug, level of education of the client, or if the client sounds convincing that the drug was meant for a relative who was already on the drug among others. It is important to know that once a drug has been categorized a POM by a relevant regulatory agency, it is no more a subjective decision of pharmacists whether to dispense with or without a valid prescription. It is sacrosanct upon the pharmacist to only dispense such with a valid prescription.

From the result, most of the pharmacists (median $=4$ on the 5-point Likert scale) 'agreed' that it is against the law to dispense POM without prescription and the practice should be discouraged. The only people who could effectively stop the practice in community pharmacies is the pharmacists themselves. The role of pharmacist in the delivery of quality healthcare cannot be overemphasised. It was President, John F. Kennedy (1962) of the United States who once said, 'The Pharmacists is an indispensable link in the chain of National Health Protection and Promotion, if we do not have the Pharmacist, it would have been necessary to invent him'. Respondent Pharmacists also 'agreed' that dispensing POM without prescription could potentially lead to drug misuse, drug abuse, and drug dependence with attendant economic consequences. Misuse and abuse of drugs contribute to drug resistance. When resistance develops it could lead to several consequences on patient and health system such as worsening illness, increase suffering for the patient, and death. Others include increase in cost of treatment, increase in duration of treatment, increased side effects as sometimes more powerful and more expensive drugs must be administered and lastly, it increases strain on health system [11], [32]-[34].

The study revealed that for some pharmacists, they would place improved access to medicine above the law that requires POM to be dispensed only with prescription. These pharmacists, $37 \%$ and $37 \%$ respectively 'agreed' that dispensing POM without prescription shortens the process of accessing POM and reduces cost of treatment ultimately. Twenty - one per cent of the respondents also think it helps clients who cannot afford to see a prescriber for whatever reason. When one juxtaposes these perceived benefits against the consequences of drug resistance as enumerated earlier, it becomes obvious that the risk by far outweighs the perceived benefits.

\section{CONCLUSION}

Self-medication is not without risks and in Nigeria, with its high-level adult illiteracy, it is manifestly more so. A vast majority of practicing community pharmacists in Nigeria are willing and do dispense prescription-only medications without a valid prescription; for a variety of reasons. This is against existing Nigerian pharmacy laws and the national drug policy. The fact that one of the reasons adduced by the surveyed pharmacists for the practice is that other pharmacists or even Patent Medicine Vendors - who by law are not authorized to have POMs - would dispense them calls for urgent attention to be paid to the enforcement of the country's drug laws and regulations; especially by the pharmacy regulatory authority - the Pharmacist's Council of Nigeria. The community pharmacists all agreed that it was illegal to dispense POMs without a valid prescription and that it carried risks to the clients and the society. Still, they were too all willing to dispense POMs without prescription indicating that they are more fundamental issues involved in their willingness to break the law and their Oaths of practice which further studies may be needed to explore and elucidate. There is need to strengthen the prescription laws in Nigeria and to clearly stipulate what constitutes a prescription and who is authorized to issue one.

\section{CONFLICT OF INTEREST}

Authors declare that they have no conflict of interest and no support was received from any funding agencies, public or private.

\section{REFERENCES}

[1] Crime UNO on D and. World Drug Report [Internet]. 2014. Available from: http://www.unodc.org/

[2] Daley, Dennis. Family and social aspects of substance use disorders and treatment. J Food Drug Anal. 2013;21(4):4.

[3] Saban A, Flisher AJ, Grimsrud A, Morojele N, London L, Williams DR, et al. Supplement article The association between substance use and common mental disorders in young adults : results from the South African Stress and Health ( SASH ) Survey. 2014;17(Supp 1):1-7.

[4] Webb L, Oyefeso A, Schifano F, Pollard M, Ghodse AH. Cause and manner of death in drug-related fatality: an analysis of drug-related deaths recorded by coroners in England and Wales in 2000. 2003;72:67-74.

[5] Morgan DJ, Okeke IN, Laxminarayan R, Perencevich EN, Weisenberg S. Non-prescription antimicrobial use worldwide: A systematic review. Lancet Infect Dis [Internet]. 2011;11(9):692-701. Available from: http://dx.doi.org/10.1016/S1473-3099(11)70054-8

[6] Okeniyi O. Addressing drug prescription problems in Nigeria. Daily Trust [Internet]. 2012 Nov 4; Available from: https://www.dailytrust.com.ng/sunday/index.php/commentdebate/5963-addressing-drug-prescription-problems-in-nigeria

[7] Patrício KP, Adriano N, Alves B, Arenales NG, Queluz TT. Teaching the Rational Use of Medicines to medical students: a qualitative research. 2012; 
[8] Al-mohamadi A, Badr A, Mahfouz L Bin, Samargandi D, Ahdal A Al. Dispensing medications without prescription at Saudi community pharmacy: Extent and perception. Saudi Pharm J [Internet]. 2013;21(1):13-8. Available from: http://dx.doi.org/10.1016/j.jsps.2011.11.003

[9] Everett CJ, Post RE, Diaz VA, Hueston WJ, Carolina S. Availability of Antibiotics for Purchase Without a Prescription on the Internet. 2009;431-5.

[10] Llor C, Cots J. The Sale of Antibiotics without Prescription in Pharmacies in Catalonia, Spain. 2009;(48):1345-9.

[11] Auta A, Abdul M, Oga E, Adewuyi EO, Abdu-aguye SN, Adeloye D, et al. Global access to antibiotics without prescription in community pharmacies: A systematic review and meta-analysis. J Infect [Internet]. 2018;0:1-11. Available from: https://doi.org/10.1016/j.jinf.2018.07.001

[12] Auta A, Banwat S, Dayom D, Shalkur D, Avu M. Occurrence and Treatment of Common Health Problems in a Nigerian Community. 2012;4(1):49-53.

[13] Auta A, Banwat S, David S, Dangiwa DA, Ogbole E, Toranyiin AJ. Antibiotics Use in Some Nigerian Communities:Knowledge and Attitudes of Consumers. Trop J Pharm Res. 2013;12(6):1087-92.

[14] World Health Organization. Lexicon of Alcohol and Drug Terms Published by the World Health Organization. 2006. [Internet]. 2006. Available

from: http://www.who.int/substance_abuse/terminology/who_lexicon/en/

[15] ThisDay. Nigeria: FG Restricts Sale of Daterape Drugs. 2013;

[16] Creswell J. Research design: Qualititative, quantitative, and mixed methods approaches. Thousand Oaks, CA: Sage; 2009.

[17] Gordis L. Epidemiology. 4th ed. Philadelphia: W.B.Saunders company; 2009.

[18] Eng J. Radiology Sample Size Estimation: How Many Individuals Should Be Studied ? 1. 2003;309-13.

[19] Erku DA, Mekuria AB, Surur AS, Gebresillassie BM. Extent of dispensing prescription-only medications without a prescription in community drug retail outlets in Addis Ababa, Ethiopia: A simulatedpatient study. Drug Healthc Patient Saf. 2016;8:65-70.

[20] Ajay S, Micah B. SAMPLING TECHNIQUES \& DETERMINATION OF SAMPLE SIZE IN APPLIED STATISTICS RESEARCH : AN OVERVIEW. 2014;II(11):1-22.

[21] Gude T, Grimstad H, Holen A, Anvik T, Baerheim A, Fasmer OB, et al. Can we rely on simulated patients' satisfaction with their consultation for assessing medical students' communication skills? A cross-sectional study. BMC Med Educ [Internet]. 2015;15(1):1-6. Available from: http://dx.doi.org/10.1186/s12909-015-0508-x

[22] Bishop PA, Herron RL. Use and Misuse of the Likert Item Responses and Other Ordinal Measures. 10(3).

[23] Ruiz M. Risks of self-medication practices. Curr Drug Saf. 2010;5(4):315-23.

[24] Adekoya-Cole, T., Akinmokun O, Enweluzo G, Badmus O, \& Alabi E. Poor Health Literacy in Nigeria: Causes, Consequences and Measures to improve it. Nig Q J Hosp Med. 2015;25(2):112-7.

[25] Organización Mundial de la Salud. Antibiotic Resistance: MultiCountry Public Awareness Survey. WHO Press. 2015;1-51.

[26] Awosan KJ, Ibitoye PK, Abubakar AK. Knowledge, risk perception and practices related to antibiotic resistance among patent medicine vendors in Sokoto metropolis, Nigeria. Niger J Clin Pract. 2018;21(11):1476-83.

[27] Abubakar U. Practices and Perception of Nigerian Community Pharmacists Towards Antimicrobial Stewardship Program. Int J Pharm Pharm Sci. 2020;(April):37-42.

[28] Beyeler N, Liu J, Sieverding M. A systematic review of the role of proprietary and patent medicine vendors in healthcare provision in Nigeria. PLoS One. 2015;10(1):1-21.

[29] Prach LM, Treleaven E, Isiguzo C, Liu J. Care-seeking at patent and proprietary medicine vendors in Nigeria Health systems and services in low and middle income settings. BMC Health Serv Res [Internet]. 2015;15(1):1-12. Available from: http://dx.doi.org/10.1186/s12913$015-0895-\mathrm{Z}$

[30] Okonkwo AD, Okonkwo UP. Patent medicine vendors, community pharmacists and STI management in Abuja, Nigeria. Afr Health Sci. 2010;10(3):253-65.

[31] Weatheral D. The inhumanity of medicine. BMJ. 1994;309:1671-2.

[32] Wang W, Arshad MI, Khurshid M, Rasool MH, Nisar MA, Aslam MA, et al. Antibiotic resistance : a rundown of a global crisis. Infect Drug Resist. 2018;1645-58.

[33] Llor C, Bjerrum L. Antimicrobial resistance: Risk associated with antibiotic overuse and initiatives to reduce the problem. Ther Adv Drug Saf. 2014;5(6):229-41.

[34] Dadgostar P. Antimicrobial resistance: implications and costs. Infect Drug Resist. 2019;12:3903-10. 